\title{
Knowledge, Practice, and Attitude Toward COVID-19 Among Physicians in Jordan and Palestine: Cross-Sectional Study
}

This article was published in the following Dove Press journal: International Journal of General Medicine

\author{
Saddam Al Demour (D) \\ Mera A Ababneh ${ }^{2}$ \\ Raed N Al-Taher $\mathbb{D}^{3}$ \\ Adel F Alrabadi (D) ${ }^{\prime}$ \\ Ahmad $F$ Jaradat (1D ${ }^{4,5}$ \\ Faris A Abushamma ${ }^{4-6}$ \\ Fadi A Al-Hadidi ${ }^{7}$ \\ Baeth M Al-Rawashdeh ${ }^{8}$ \\ Mohammad A Ihmeidan (D) \\ Ahmad K Abubaker 9 \\ Mohammad T Al-Zubi ${ }^{10}$ \\ 'Department of Special Surgery, Division of \\ Urology, School of Medicine, The \\ University of Jordan, Amman I 1942, Jordan; \\ ${ }^{2}$ Department of Clinical Pharmacy, Jordan \\ University of Science and Technology, \\ Faculty of Pharmacy, Irbid 22 I I0, Jordan; \\ ${ }^{3}$ Department of General Surgery, Division \\ of Pediatric Surgery, School of Medicine, \\ The University of Jordan, Amman II 942 , \\ Jordan; ${ }^{4}$ Department of Medicine, Faculty of \\ Medicine and Health Sciences, An-Najah \\ National University, Nablus 44833, \\ Palestine; ${ }^{5}$ Department of Urology, An- \\ Najah National University Hospital, Nablus \\ 44833, Palestine; ${ }^{6}$ Bristol Urological \\ Institute, North Bristol NHS Trust, Bristol, \\ UK; ${ }^{7}$ Department of Special Surgery, \\ Division of Orthopedics, School of \\ Medicine, The University of Jordan, Amman \\ I 1942, Jordan; ${ }^{8}$ Department of Special \\ Surgery, Division of Otorhinolaryngology, \\ School of Medicine, The University of \\ Jordan, Amman I 1942, Jordan; \\ ${ }^{9}$ Department of Anesthesia, Faculty of \\ Medicine, Jordan University of Science and \\ Technology, Irbid 22I I0, Jordan; \\ ${ }^{10}$ Department of Urology, Faculty of \\ Medicine, Yarmouk University, Irbid 21 I63, \\ Jordan
}

Correspondence: Saddam Al Demour

Email saldemour@ju.edu.jo
Background and Objectives: Coronavirus disease-2019 (COVID-19) is an emerging disease threatening the world with a rapid increase in cases and deaths since it was first identified in December 2019. Adequate knowledge, practice, and attitudes (KPA) toward COVID-19 among physicians at the frontline defense against the COVID-19 pandemic may enhance their ability to avoid the risk of self-infection, decrease mortality, and provide adequate medical care service in this pandemic. This study aimed to assess KPA toward COVID-19 among physicians in Jordan and Palestine.

Methods: This is a cross-sectional study using an online survey conducted from 10 April to 26 April 2020 among Jordan and Palestine physicians. Invitations were sent to physician groups on Facebook and WhatsApp. This survey contains 36-items, divided into four main sections to assess the participants' socio-demographic characteristics, knowledge, practice, and attitude about COVID-19.

Results: A total of 454 physicians participated in this study. The mean score of basic knowledge was $4.4 \pm 0.8$ (range 2-4). There were significant differences between basic knowledge mean scores among physicians in different professional degrees and physicians in various health sectors $(\mathrm{P}=0.0315, \mathrm{P}=0.0137$, respectively). The mean scores of selfprotection measures, were $6.1 \pm 1.1$ (range 3-7) and measures if physician self-suspected of COVID-19 were 9.9 \pm 1.1 (range 5-11). The mean score of attitudes toward COVID-19 was $41.5 \pm 3.3$ (range 21-45) and significantly related to the age and different experience years $(\mathrm{P}=0.0022, \mathrm{P}=0.0077$, respectively).

Conclusion: As the global threat of COVID-19 continues to emerge, physicians from Jordan and Palestine showed adequate KPA toward COVID-19. There was a significant difference in knowledge level and attitude between physicians. Policymakers and physicians should keep continuous educational activities, training, and follow-up updates during this pandemic.

Keywords: coronavirus, COVID-19, knowledge, practice, attitudes, physicians

\section{Introduction}

In December 2019, a cluster of pneumonia cases, caused by a newly identified $\beta$ coronavirus, occurred in Wuhan, China. ${ }^{1}$ The World Health Organization (WHO) officially named the disease as coronavirus disease 2019 (COVID-19), and the International Committee on Taxonomy of Viruses named the virus as severe acute respiratory syndrome coronavirus 2 (SARS-CoV-2). ${ }^{2}$ On 11 March 2020, the WHO declared the epidemic of COVID-19 as a pandemic. ${ }^{3}$ 
SARS-CoV-2 belongs to a species of severe acute respiratory syndrome-related coronavirus (SARS-CoV) and genus $\beta$-coronavirus. ${ }^{4}$ Like SARS-CoV and Middle East respiratory syndrome coronavirus (MERS-CoV), the main symptoms of COVID-19 included fever, fatigue, and cough, and can cause acute respiratory distress syndromes (ARDS). ${ }^{5}$ Recent data reported that human-to-human transmission was considered as a major transmission mode. COVID-19 primarily spreads through the respiratory tract by droplets, respiratory secretions, and direct contact. ${ }^{6}$ According to a recent Chinese study, about $80 \%$ of patients present with mild disease, and the overall casefatality rate is about $2.3 \%$ but reaches $8.0 \%$ in patients aged 70 to 79 years and $14.8 \%$ in those aged $\geq 80$ years. $^{7}$

Physicians are essential for any health-care system and at the frontline defense against the COVID-19 pandemic. They play a crucial role in diagnosis, treatment, prevention of disease spread, and public education during this pandemic. Moreover, they are frequently exposed to infected individuals with COVID-19, making them at higher risk of infection than others. ${ }^{8}$

COVID-19 transmission among health-care workers (HCWs) can result from direct contact with infected patients, lack of personal protective equipment, overcrowding, absence of isolation room facilities, and environmental contamination. ${ }^{7}$ In the United States of America (USA), more than 288,066 HCWs have been infected, and close to 955 have died from COVID-19, according to most new data, from the Centers for Disease Control and Prevention (CDC). ${ }^{9}$ Therefore, it is important to protect HCWs to ensure patients' care continuity and prevent infection transmission to other patients. COVID-19 among HCWs had been reported in several studies. Yoshida et al reported 120 deaths among physicians with a $44 \%$ mortality rate up to 3 April 2020, in the early phase of COVID-19. ${ }^{10}$ Furthermore, the Indian Medical Association (IMA) National COVID-19 registry data suggests more than 1000 doctors have been infected with COVID-19. ${ }^{11}$

Furthermore, Ing et al reported that COVID-19 is associated with significant mortality among physicians and other HCWs worldwide. The authors reported the countries with the most physicians' deaths were Italy $(121 / 278$; $44 \%)$, Iran (43/278; 15\%), Philippines (21/278; 8\%), Indonesia $(17 / 278 ; 6 \%)$, China $(16 / 278 ; 6 \%)$, Spain (12/ $278 ; 4 \%)$, USA $(12 / 278 ; 4 \%)$ and UK $(11 / 278 ; 4 \%){ }^{12}$ Thus, a shortage of physicians may lead to worse outcomes in health-care systems.
Hence, we suggest that adequate Physicians' KPA toward COVID-19 would enhance their ability to avoid the risk of self-infection, decrease mortality, and provide adequate medical care service in this pandemic. This study aimed to assess the KPA toward COVID-19 among physicians in Jordan and Palestine.

\section{Materials and Methods Study Design and Population}

This is a cross-sectional study through an online survey conducted in Jordan and Palestine from 10 April to 26 April 2020 to obtain responses from practicing physicians from different health-care sectors such as public, private, university, and military sectors. In this online survey, Google forms were used to collect the participants' data with a consent form appended. The invitations were sent to physician closed groups on Facebook and WhatsApp. These closed groups were created by members of the Jordan Medical Association and Palestine Medical Association. All participants confirmed working in Jordan or Palestine. Study objectives were clearly explained at the beginning of the survey, and the participants were encouraged to roll out the survey to as many physicians as possible. Thus, the link was forwarded to physicians apart from the first point of contact and so on.

\section{Study Instrument}

This survey was designed to evaluate the knowledge, practice, and attitudes of physicians towards COVID-19. It was developed in the English language after a thorough search in the recent literature and based on the most recently available information from the $\mathrm{WHO}$ on emerging respiratory viruses, including COVID-19. The developed draft survey instrument was sent to a group of experts chosen according to their experience and expertise in the related fields to assess its readability, simplicity, relativity, and importance. A pilot study was carried out by randomly selected 20 participants at Jordan university hospital to assess clarity, readability, and acceptability. Refinements were made to facilitate better comprehension and organize the questions before the final survey was distributed to the study population. The data of the pilot analysis were not used for the final sample of the study.

\section{Contents of the Survey Instrument and Scoring System}

The survey instrument consisted of 36 closed-ended questions with responses based on Likert, multiple-choice, and 
yes/no/I do not know format. This survey was divided into four main sections to assess the participants' sociodemographic characteristics, knowledge, practice, and attitude toward COVID-19 and took approximately 12 minutes to complete. The first section covered the participants' socio-demographic and profession-related characteristics, including age, gender, working place, marital status, presence of children, health-care sector, years of work experience, professional degree, place of residency, and monthly income. The second section included 13 items assessing participants' basic and general knowledge of COVID-19. The basic knowledge part consists of 6 items about the geographical origin, incubation period, official name, natural host of the virus, diagnosis, and WHO classification. These were scored by assigning one point for each correct answer and zero points for an incorrect answer, with scores ranging from 0 to 6 . A cut-off level of $\geq 4$ was considered to indicate adequate basic knowledge, whereas $<4$ was considered inadequate knowledge. General knowledge of COVID-19 included seven items assessing transmission routes, symptoms, complications, a group at high risk, comorbidities, treatment, and medical information source. The third section consisted of 4 domains assessing practice toward COVID-19, included indications for PCR test ( 7 items), indications for home quarantine (7 items), self-protection measures (7 items), and practices in case of self-suspect of COVID-19 (11 items). A summary score was calculated for each study participant by assigning a value of one to each corrected response, then adding a total score for each domain. The last section included nine items assessing physicians' attitudes toward COVID19, where a 5 point Likert scale ranging from 1 (disagree) to 5 (agree) except for one item was reversed.

\section{Ethical Considerations}

The survey was anonymous to maintain the privacy and confidentiality of all information collected in the study. Eligible participant in this survey was voluntary and was not compensated. Informed consent was obtained from each participant before participation. Ethical approval was obtained from the Institutional Review Board at Jordan university hospital (reference number: 10/2020/ 8187). The study was performed following the Helsinki Declaration as revised in 2013.

\section{Data Analysis}

The obtained data were coded, validated, and analyzed using SPSS version 24 (IBM, Armonk, NY, USA).
Descriptive analysis was applied to calculate the frequencies for categorical variables, the mean and standard deviation for continuous variables. T-test or Analysis of Variance (ANOVA) test was used to examine the effect of demographic characteristics on participants' basic knowledge and attitude scores in the univariate analysis. Tukey's post hoc analysis was conducted for statistically significant variables. Variables with $p$-value $\leq 0.2$ were entered in the multivariable linear regression model in a stepwise process. A p-value of less than 0.05 was considered the cutoff level for statistical significance.

\section{Results}

\section{Participant's Characteristics}

A total of 454 physicians were enrolled in this study, including $354(78 \%)$ men and $100(22 \%)$ women with a mean age of $36.2 \pm 10.8$. The professional degree of the participants were resident doctors 148 (32.6\%), specialist doctors 133 (29.3\%), and consultant doctors 111 (24.4\%). One hundred and fifty-four (33.9\%) participants work in the private sector while $140(30.8 \%)$ in university hospitals. Table 1 details the socio-demographic and professional characteristics of participants.

\section{Basic and General Knowledge About COVID-19}

When asked about basic knowledge of COVID-19, only 71 participants $(15.6 \%)$ reported that SARS-COV-2 is the official name of the virus according to the WHO, and almost all of the participants responded that the geographical origin of COVID-19 was from Wuhan in China. The majority of participants (96.9\%) mentioned that the RT-PCR test is the available diagnostic test. The mean scores of the participants' basic knowledge were $4.4 \pm$ 0.8 (range 2-6). The frequency of correct answers that assessed basic and general knowledge on COVID-19 are shown in Table 2.

Almost all participants reported that droplets spread by coughing or sneezing, person to person, and contact with the contaminated surface are the main transmission routes. Regarding the symptoms of COVID-19, about $98 \%$ of participants answered that fever, shortness of breath, cough, myalgia were the main symptoms, while 307 (67\%) reported that COVID-19 could be presented without symptoms. More than ninety percent of the participants reported that pneumonia, respiratory failure, and acute respiratory distress syndrome are some of the 
Table I Sociodemographic Characteristics of Participants $(n=454)$

\begin{tabular}{|c|c|}
\hline Characteristics & Participants, n (\%) \\
\hline Age group (years) (Mean \pm SD) & $36.2 \pm 10.8$ \\
\hline $22-35$ & $263(57.9)$ \\
\hline $36-50$ & | 43 (3|.5) \\
\hline$>50$ & $48(10.6)$ \\
\hline \multicolumn{2}{|l|}{ Gender } \\
\hline Male & $354(78)$ \\
\hline Female & $100(22)$ \\
\hline \multicolumn{2}{|l|}{ Working place } \\
\hline Jordan & $366(80.6)$ \\
\hline Palestine & $88(19.4)$ \\
\hline \multicolumn{2}{|l|}{ Place of residence } \\
\hline Urban & $426(93.8)$ \\
\hline Rural & $28(6.2)$ \\
\hline \multicolumn{2}{|l|}{ Professional degree } \\
\hline Consultant & III (24) \\
\hline Specialist & $133(29.3)$ \\
\hline Resident & $148(32.6)$ \\
\hline Intern & $62(13.7)$ \\
\hline \multicolumn{2}{|l|}{ Health-care sector } \\
\hline Public sector & $132(29.1)$ \\
\hline Military sector & $28(6.2)$ \\
\hline University sector & $140(30.8)$ \\
\hline Private sector & $154(33.9)$ \\
\hline \multicolumn{2}{|l|}{ Marital status } \\
\hline Married & $273(60.5)$ \\
\hline Single & $175(38.8)$ \\
\hline Divorced & $3(0.7)$ \\
\hline \multicolumn{2}{|l|}{ Presence of children } \\
\hline Yes & $209(46)$ \\
\hline No & $245(54)$ \\
\hline \multicolumn{2}{|l|}{ Monthly income (JD) } \\
\hline Less than 500 & $84(18.5)$ \\
\hline $500-1000$ & $146(32.2)$ \\
\hline$>1000$ & $224(49.3)$ \\
\hline \multicolumn{2}{|l|}{ Experience (years) } \\
\hline$<5$ & $226(49.8)$ \\
\hline $5-9$ & $81(17.8)$ \\
\hline $10-14$ & $55(12.1)$ \\
\hline$>15$ & $92(20.3)$ \\
\hline
\end{tabular}

Abbreviations: SD, standard deviation; JD, Jordanian Dinar.

complications of COVID-19. When they were asked about the groups at high risk of COVID-19, they mentioned elderly 439 (96.7), pregnant females 187 (41.2\%), and only $22.5 \%$ of them reported that children are one of the high-risk groups. A total of $411(90.5 \%)$ reported that Hydroxychloroquine and Azithromycin were used as a possible treatment against COVID-19, and 395 (87\%) mentioned that there is no definitive treatment available yet. Regarding the reliable information about COVID-19, the participants reported medical journals $413(91 \%)$, WHO official websites 444 (97.8\%), and only 12 (2.6\%) reported social media as a reliable source of information. The frequency of correct answers that assessed basic and general knowledge on COVID-19 are shown in Table 2.

\section{Practice Towards COVID-19}

When participants were asked about the indications for the real-time reverse transcription-polymerase chain reaction (RT-PCR) test method, they reported that it should be done for anyone who had recently returned from international travel and has symptoms 380 (83.7\%). Also, they reported that anyone with flu-like symptoms $280(61.7 \%)$, and the incidence of acute respiratory infection without other causes that fully explain the clinical symptoms 366 (80.6\%). Furthermore, $444(97,8 \%)$ reported that anyone who had recently returned from international travel without symptoms, and 428 (94.3\%) reported that any person without symptoms had contact with COVID-19 patient were indicated for home quarantine. The frequency of responses that assessed physician's practice toward COVID-19 are shown in Table 3.

\section{Attitudes Towards COVID-19}

The majority of participants, 435 (95.8\%), agreed that COVID-19 is a serious health issue if it spreads to society. Also, 399 (87.9\%) believed that the cure rate of COVID19 is high, and elderly patients with comorbidities have a higher risk of death from COVID-19 than others. A total of $444(97.8 \%)$ thought physicians have an important role in educating patients and community members about the prevention measures against COVID-19. Of participants, 97 (21.4\%) will refrain from dealing with COVID-19suspected patients, and 334 (73.6) were worried about being infected with COVID-19 while dealing with patients in the workplace. Frequency of responses that assessed attitudes toward COVID-19 are shown in Table 4.

Basic knowledge and attitude scores were compared among different socio-demographic and professional characteristics of participants, as depicted in Table 5. There were significant statistical differences between basic knowledge and attitudes mean scores among physicians in different professional degrees. According to the post-hoc 
Table 2 Basic and General Knowledge of COVID-19 ( $n=454)$

\begin{tabular}{|c|c|c|c|}
\hline Basic Knowledge of COVID-19 & \multicolumn{3}{|c|}{ Correct Answers N (\%) } \\
\hline COVID-19 classified by WHO as pandemic & \multicolumn{3}{|l|}{$397(87.4)$} \\
\hline The geographical origin of COVID-19 from Wuhan-China & \multicolumn{3}{|l|}{$452(99.5)$} \\
\hline The official name used by the WHO for the virus is SARS-COV2 & \multicolumn{3}{|l|}{$71(15.6)$} \\
\hline The potential natural host of SARS-COV2 is thought to be from animal & \multicolumn{3}{|l|}{$249(54.8)$} \\
\hline The incubation period of SARS-COV2 is $2-14$ days & \multicolumn{3}{|l|}{$400(88.1)$} \\
\hline The diagnosis of COVID-19 confirmed by PCR & \multicolumn{3}{|l|}{$440(96.9)$} \\
\hline Mean $\pm \mathrm{SD}$ of basic knowledge score & \multicolumn{3}{|l|}{$4.4 \pm 0.8$} \\
\hline Range & \multicolumn{3}{|l|}{$2-6$} \\
\hline \multirow[t]{2}{*}{ General Knowledge of COVID-I9 } & No & Yes & Do Not Know \\
\hline & $\mathbf{N}(\%)$ & $\mathbf{N}(\%)$ & $\mathbf{N}(\%)$ \\
\hline \multicolumn{4}{|l|}{ Possible routes of transmission of SARS-COV2 are: } \\
\hline Human body fluids & $122(26.9)$ & $275(60.6)$ & $57(12.6)$ \\
\hline From human to human & $7(1.5)$ & $445(98.1)$ & $2(0.4)$ \\
\hline Contaminated surfaces & $4(0.9)$ & $450(99.1)$ & - \\
\hline Airborne route & $63(13.9)$ & $364(80.2)$ & $27(5.9)$ \\
\hline Droplets spread by coughing or sneezing & $5(1.1)$ & $448(98.7)$ & $\mathrm{I}(0.2)$ \\
\hline Fecal-oral & $211(46.6)$ & $145(31.9)$ & $98(21.6)$ \\
\hline From mother to fetus & $222(48)$ & $70(15.4)$ & $162(35.7)$ \\
\hline \multicolumn{4}{|l|}{ Possible symptoms of COVID-19 are: } \\
\hline Headache & $48(10.6)$ & $393(86.6)$ & $13(2.9)$ \\
\hline Sputum & $320(70.5)$ & II $5(25.3)$ & $19(4.2)$ \\
\hline Cough & $5(1.1)$ & $447(98.5)$ & $4(0.9)$ \\
\hline Shortness of breathiness & - & $449(98.9)$ & $5(1.1)$ \\
\hline Fever & $4(0.9)$ & $448(98.7)$ & $2(0.4)$ \\
\hline Myalgia & $8(1.8)$ & $44 \mid(97.1)$ & $5(1.1)$ \\
\hline Diarrhea & $97(21.4)$ & $325(71.6)$ & $32(7)$ \\
\hline No symptoms & $307(67.6)$ & $129(28.4)$ & $18(4)$ \\
\hline \multicolumn{4}{|l|}{ Patients with the following comorbidities are more likely affected by COVID-19: } \\
\hline Arterial hypertension & $93(20.5)$ & $320(70.5)$ & $4 \mid(9)$ \\
\hline Diabetes mellitus & $33(7.3)$ & $395(87)$ & $26(5.7)$ \\
\hline COPD & $4(0.9)$ & $446(98.2)$ & $4(0.9)$ \\
\hline Renal failure & $67(14.8)$ & $338(74.4)$ & $49(10.8)$ \\
\hline Respiratory failure & $2(0.4)$ & $445(98)$ & $7(1.6)$ \\
\hline Ischemic heart disease & $56(12.3)$ & $359(79.1)$ & $39(8.6)$ \\
\hline Bronchial asthma & $15(3.3)$ & $413(9 \mid)$ & $26(5.7)$ \\
\hline Malignances & $30(6.6)$ & $393(86.6)$ & $31(6.8)$ \\
\hline \multicolumn{4}{|l|}{ Possible complications of COVID-19 are: } \\
\hline Pneumonia & $15(3.3)$ & $427(94)$ & $12(27.3)$ \\
\hline Multi-organ failure & $83(18.3)$ & $333(73.3)$ & $38(8.4)$ \\
\hline Septic shock & $|3|(28.9)$ & $220(48.4)$ & $103(22.7)$ \\
\hline Respiratory failure & - & $452(99.6)$ & $2(0.4)$ \\
\hline Renal failure & $104(22.9)$ & $292(64.3)$ & $58(12.8)$ \\
\hline Acute respiratory distress syndrome (ARDS) & II (2.4) & $435(95.8)$ & $8(1.8)$ \\
\hline \multicolumn{4}{|l|}{ The age group at high risk of COVID-19: } \\
\hline Neonates & $335(73.8)$ & $75(16.5)$ & $44(9.7)$ \\
\hline Children & $337(74.2)$ & $102(22.5)$ & $15(3.3)$ \\
\hline Adults & $153(33.7)$ & $293(64.5)$ & $8(1.8)$ \\
\hline
\end{tabular}

(Continued) 
Table 2 (Continued).

\begin{tabular}{|l|l|l|l|}
\hline Basic Knowledge of COVID-I9 & \multicolumn{2}{l|}{ Correct Answers N (\%) } \\
\hline Elderly & $\begin{array}{l}\text { (1.8) } \\
149(32.8)\end{array}$ & $\begin{array}{l}439(96.7) \\
187(4 I .2)\end{array}$ & $7(1.5)$ \\
Pregnant women & & & \\
\hline Current treatments used for COVID-19 & & \\
Anti-viral agents (Oseltamivir, Lopinavir) & $214(47.1)$ & $192(42.3)$ & $48(10.6)$ \\
Anti-bacterial agents & $310(68.3)$ & $122(26.9)$ & $22(4.8)$ \\
Vitamin supplements & $167(36.8)$ & $24 I(53.1)$ & $46(10.1)$ \\
Hydroxychloroquine & $76(16.7)$ & $362(79.7)$ & $16(3.5)$ \\
Hydroxychloroquine and azithromycin & $29(6.4)$ & $4 I I(90.5)$ & $14(3.1)$ \\
Chloroquine & $213(46.9)$ & $174(38.3)$ & $67(14.8)$ \\
No definitive treatment yet & $52(11.5)$ & $395(87)$ & $7(1.5)$ \\
\hline
\end{tabular}

Abbreviations: SD, standard deviation; COVID-19, coronavirus disease 2019; COPD, chronic obstructive pulmonary disease.

analysis, consultants had statistically significantly higher knowledge and attitude scores than interns $(p=0.0331$, $\mathrm{p}=0.0054$, respectively). Further, there was a significant statistical difference between basic knowledge mean scores among physicians in different health sectors, particularly public vs university hospitals $(p=0.0116)$. On the other hand, the attitude mean scores were significantly related to the age groups $(22-35$ vs $36-50$ years, $\mathrm{p}=0.0310)$ and different experience years $(<5$ years vs $>15$ years and 5-9 years vs $>15$ years, $\mathrm{p}=0.0312, \mathrm{p}=0.0342$, respectively). Physicians with monthly income $>1000$ JD reported higher attitude scores than those with monthly income $<500 \mathrm{JD}$ $(\mathrm{P}=0.015)$. When conducting a multiple regression analysis for knowledge scores, no variable was statistically significant. In contrast, only the living area was statistically significant in the linear regression analysis for attitude scores $(\mathrm{p}=0.0397)$.

\section{Discussion}

COVID-19 is a pandemic illness that has caused 1,711,498 deaths worldwide till 23 December $2020 .{ }^{13}$ At the beginning of the COVID-19 pandemic, there were a relatively small number of confirmed cases in Jordan and Palestine, which may be attributed to the government measures taken at that time. Recently, it has been observed that the confirmed cases have increased to worrying numbers, bringing the total number of cases in Jordan to 281,983 and the total number of deaths to 3652 till 22 December 2020. ${ }^{14}$ Palestinian Ministry of Health reported that the daily numbers of confirmed cases rise significantly, bringing the total number to 143,718 and the total number of deaths to 1347 till 25 November $2020 .{ }^{15}$

In our study, most of the participants had adequate basic knowledge of COVID-19. The incubation period for SARS-CoV-2 is thought to be within 14 days following exposure, and the symptoms appear after an incubation period of approximately 5.2 days. ${ }^{16}$ In a study conducted by Khader et al, $36 \%$ of dentists thought that $2-14$ days is the incubation period of the virus, which is very important in determining the safe period to treat suspected patients. ${ }^{17}$ In contrast, most participants in our study reported that the incubation period of the virus from 2 to 14 days.

Currently, Person-to-person transmission occurs primarily via direct contact or through droplets spread by coughing or sneezing from an infected individual. ${ }^{18}$ Hence, physicians need to recognize the possible transmission routes since direct contact with the patients during clinical examination, medical and surgical procedures make the physicians more vulnerable than others. Maleki et al reported that $99 \%$ of participants had an excellent knowledge level regarding the modes of transmission. ${ }^{19}$ On the other hand, Bhagavaathula et al reported that a significant proportion of HCWs in the United Arab Emirates had poor knowledge of transmission. ${ }^{20}$ The majority of participants reported the most important transmission routes that are important to recognize the threat and take the necessary precautions and considered the cornerstone to control the disease's spread.

Furthermore, early recognition of COVID-19 symptoms is the main step in the patients' management. This causes the physicians to take the necessary precautions to protect themselves and others from disease transmission. ${ }^{21}$ Almost all of the participants reported the most common symptoms of COIVD-19, such as fever, shortness of breath, myalgia, and $67.6 \%$ reported that the patient could be presented without symptoms. This finding was similar to several studies where they reported that the 
Table 3 Participants Frequency and Mean Scores of Practices for COVID-19 ( $n=454)$

\begin{tabular}{|c|c|c|c|}
\hline People Who Should Be Kept in the Home Quarantine & $\begin{array}{l}\text { No } \\
\text { N (\%) }\end{array}$ & $\begin{array}{l}\text { Yes } \\
\mathbf{N}(\%)\end{array}$ & $\begin{array}{l}\text { Do Not Know } \\
\text { N (\%) }\end{array}$ \\
\hline Anyone who had recently returned from international travel without symptoms & $10(2.2)$ & $444(97.8)$ & - \\
\hline Any person without symptoms had contact with a patient with COVID-19 & $26(5.7)$ & $428(94.3)$ & - \\
\hline Anyone who had recently returned from international travel and has symptoms & $230(50.7)$ & $22 I(48.6)$ & $3(0.7)$ \\
\hline Anyone with flu-like symptoms & 203(44.7) & $246(54.2)$ & $5(I . I)$ \\
\hline Anyone who works in a hospital has confirmed cases of COVID-I9 & 124(27.3) & $317(69.8)$ & $13(2.9)$ \\
\hline $\begin{array}{l}\text { Incidence of acute respiratory infection without other causes that fully explain the clinical } \\
\text { symptoms }\end{array}$ & $219(48.2)$ & 222(48.9) & $13(2.9)$ \\
\hline Being in close contact with a confirmed case of COVID-19 & $82(18)$ & $364(80.2)$ & $8(1.8)$ \\
\hline Mean \pm SD, (range) & \multicolumn{3}{|c|}{$5.0 \pm I(I-7)$} \\
\hline \multicolumn{4}{|l|}{ Indications for RT-PCR test } \\
\hline Any person without symptoms who had contact with COVID-I9 patients. & $360(79.3)$ & $89(19.6)$ & $5(1.1)$ \\
\hline Anyone who had recently returned from international travel without symptoms & $389(85.7)$ & $62(13.7)$ & $3(0.7)$ \\
\hline Anyone who had recently returned from international travel and has symptoms & $7 I(15.6)$ & $380(83.7)$ & $3(0.7)$ \\
\hline Being in close contact with someone who had traveled over the past 14 days & $350(77.1)$ & $99(21.8)$ & $5(I . I)$ \\
\hline Anyone with flu-like symptoms & $167(36.8)$ & $280(61.7)$ & $7(1.5)$ \\
\hline Anyone who works in a hospital that has confirmed cases of COVID-19 & $311(68.5)$ & $|3|(28.9)$ & $12(2.6)$ \\
\hline $\begin{array}{l}\text { Incidence of acute respiratory infection without other causes that fully explain the clinical } \\
\text { symptoms }\end{array}$ & $75(16.5)$ & $366(80.6)$ & $13(2.9)$ \\
\hline Mean \pm SD, (range) & \multicolumn{3}{|c|}{$5.4 \pm 1.4(I-7)$} \\
\hline \multicolumn{4}{|l|}{ Methods of self-protection from COVID-I9 in work } \\
\hline Stop shaking hands and kissing & $3(0.7)$ & $45 I(99.3)$ & - \\
\hline Frequent hand washing & $8(1.8)$ & $446(98.2)$ & - \\
\hline Wearing gloves all the time & $162(35.7)$ & $283(62.3)$ & $9(2)$ \\
\hline Wear a face mask all the time & I54(33.9) & $290(63.9)$ & $10(2.2)$ \\
\hline Wear a highly effective face mask like (N95) & $54(I 1.9)$ & $394(86.8)$ & $6(1.3)$ \\
\hline Avoid contact with eyes, nose, or mouth & $3(0.7)$ & $447(98.4)$ & $4(0.9)$ \\
\hline Avoid crowded places in the hospital (elevators, restaurants) & $3(0.7)$ & $447(98.4)$ & $4(0.9)$ \\
\hline Mean \pm SD, (range) & \multicolumn{3}{|c|}{$6.1 \pm 1.1(3-7)$} \\
\hline \multicolumn{4}{|l|}{ If I suspect myself with COVID-19, I will do the followings } \\
\hline Cover mouth and nose while coughing & $4(0.9)$ & $450(99.1)$ & - \\
\hline Seek medical attention right away even if the symptoms are mild & $73(16.1)$ & $376(82.8)$ & $5(1.1)$ \\
\hline Isolate myself and ask for sick leave & $39(8.6)$ & $410(90.3)$ & $5(I . I)$ \\
\hline Take antibiotics & $402(88.5)$ & $43(9.5)$ & $9(2)$ \\
\hline Take some herbal medicine & $329(72.5)$ & $108(23.8)$ & $17(3.7)$ \\
\hline I wear a face mask all the time to protect others & $17(3.7)$ & $433(95.4)$ & $4(0.9)$ \\
\hline Frequent cleaning of household surfaces and workplaces & $6(1.3)$ & $446(98.2)$ & $2(0.4)$ \\
\hline Stop any kind of gatherings, activities or social events & - & $449(98.9)$ & $5(1.1)$ \\
\hline I take certain medications such as antipyretics and cough medicines & $81(17.8)$ & $360(79.3)$ & $13(2.9)$ \\
\hline Request a test & $29(6.4)$ & $423(93.2)$ & $2(0.4)$ \\
\hline Nothing, just wait & $4 \mid 4(9 \mid .2)$ & $29(6.4)$ & $\mathrm{II}(2.4)$ \\
\hline Mean \pm SD, (range) & \multicolumn{3}{|c|}{$9.9 \pm I . I(5-I I)$} \\
\hline
\end{tabular}

Abbreviations: SD, standard deviation; COVID-19, coronavirus disease 2019.

spectrum of clinical presentations of COVID-19 ranging from asymptomatic infection to severe respiratory failure. $^{22,23}$
It is worth recognizing the age groups at risk to spread awareness, take the necessary action, and give them appropriate care. Our participants reported that older adults are 
Table 4 Frequency of Participants Attitudes Toward COVID-19 $(n=454)$

\begin{tabular}{|c|c|}
\hline Statements & $\begin{array}{l}\text { Agree, } \\
\text { n (\%) }\end{array}$ \\
\hline $\begin{array}{l}\text { I think COVID- } 19 \text { is a serious health issue if it spreads } \\
\text { to the society }\end{array}$ & $435(95.8)$ \\
\hline $\begin{array}{l}\text { I think COVID-19 is a more serious health issue when } \\
\text { compared to seasonal flu }\end{array}$ & $387(85.2)$ \\
\hline I think the cure rate of COVID- 19 is high & $399(87.9)$ \\
\hline $\begin{array}{l}\text { I think that the elderly and patients with } \\
\text { comorbidities have more risk of death from COVID- } \\
\text { I9 than others }\end{array}$ & $446(98.2)$ \\
\hline $\begin{array}{l}\text { I think physicians have an important role in educating } \\
\text { patients and members of the community about the } \\
\text { prevention measures against COVID-19 }\end{array}$ & $444(97.8)$ \\
\hline $\begin{array}{l}\text { In case of an outbreak, all physicians of various } \\
\text { specialties should have a vital role. }\end{array}$ & $377(83.1)$ \\
\hline $\begin{array}{l}\text { Access to the latest reports and studies from the } \\
\text { World Health Organization is necessary to increase } \\
\text { awareness about COVID-19 disease }\end{array}$ & $445(98)$ \\
\hline $\begin{array}{l}\text { I feel worried about being infected with COVID-I9 } \\
\text { while dealing with patients in my workplace: } \\
\text { I will refrain from dealing with COVID-19-suspected } \\
\text { patients }\end{array}$ & $\begin{array}{l}334(73.6) \\
97(21.4)\end{array}$ \\
\hline Score of attitudes mean $\pm S D$, range & $\begin{array}{l}41.5 \pm 33 \\
(21-45)\end{array}$ \\
\hline
\end{tabular}

Abbreviations: SD, standard deviation; COVID-19, coronavirus disease 2019.

more susceptible to COVID-19 than other age groups. Several studies suggest that individuals of any age can acquire COVID-19, and older age is associated with increased mortality. ${ }^{24,25}$ Besides, findings were reported from Italy, with case fatality rates of $12 \%$ and $20 \%$ among those aged 70 to 79 years and 80 years or older, respectively. ${ }^{26}$ Children of all ages can get COVID-19; they appear to be affected less commonly than adults. ${ }^{27}$ In a systematic literature review, children accounted for $1 \%$ to $5 \%$ of diagnosed COVID-19 cases. $^{28}$ Around twothirds of our participants reported that children were not at higher risk groups of COVID-19.

Physicians face challenges through daily practices with COVID-19 patients. For instance, physicians should monitor themselves for fever and symptoms of COVID-19 and stay home if they are ill. ${ }^{29}$ In our study, the majority of participants reported that they would take sick leave and isolation for two weeks in case of self-suspicion of COVID-19. In one report of $48 \mathrm{HCWs}$ with confirmed COVID-19 in King County, Washington, USA, 65\% reported working for a median of two days while exhibiting symptoms of COVID-19. ${ }^{30}$ Also, personal protection
Table 5 Basic Knowledge and Attitudes Toward COVID-19 by Participants Characteristics $(n=454)$

\begin{tabular}{|c|c|c|c|c|}
\hline Variables & $\begin{array}{l}\text { Basic } \\
\text { Knowledge } \\
\text { Mean士SD }\end{array}$ & P-value & $\begin{array}{l}\text { Attitudes } \\
\text { Mean } \pm \text { SD }\end{array}$ & p-value \\
\hline \multicolumn{5}{|l|}{ Age(years) } \\
\hline $22-35$ & $4.4 \pm 0.9$ & 0.7907 & $41.0 \pm 3.5$ & 0.0022 \\
\hline $36-50$ & $4.4 \pm 0.8$ & & $41.9 \pm 2.9$ & \\
\hline$>50$ & $4.5 \pm 0.8$ & & $42.5 \pm 2.4$ & \\
\hline \multicolumn{5}{|l|}{ Gender } \\
\hline Male & $4.4 \pm 0.9$ & 0.4632 & $41.5 \pm 3.2$ & 0.9829 \\
\hline Female & $4.4 \pm 0.8$ & & $41.5 \pm 3.3$ & \\
\hline \multicolumn{5}{|l|}{$\begin{array}{l}\text { Professional } \\
\text { degree }\end{array}$} \\
\hline Consultant & $4.6 \pm 0.8$ & 0.0315 & $42.3 \pm 2.8$ & 0.0065 \\
\hline Specialist & $4.4 \pm 0.8$ & & $41.4 \pm 3.2$ & \\
\hline Resident & $4.4 \pm 0.9$ & & $41.3 \pm 3.4$ & \\
\hline Intern & $4.3 \pm 0.9$ & & $40.6 \pm 3.8$ & \\
\hline \multicolumn{5}{|l|}{$\begin{array}{l}\text { Health-care } \\
\text { sector }\end{array}$} \\
\hline Public & $4.2 \pm 0.9$ & 0.0137 & $41.5 \pm 3.4$ & 0.7236 \\
\hline Military & $4.6 \pm 0.8$ & & $4 I .4 \pm 2.6$ & \\
\hline University & $4.6 \pm 0.8$ & & $41.7 \pm 3.3$ & \\
\hline Private & $4.4 \pm 0.8$ & & $41.2 \pm 3.3$ & \\
\hline \multicolumn{5}{|l|}{ Living Area } \\
\hline Urban & $4.4 \pm 0.8$ & 0.2606 & $41.4 \pm 3.3$ & 0.1344 \\
\hline Rural & $4.3 \pm 0.9$ & & $42.4 \pm 2.9$ & \\
\hline \multicolumn{5}{|l|}{$\begin{array}{l}\text { Experience } \\
\text { (years) }\end{array}$} \\
\hline$<5$ & $4.4 \pm 0.9$ & 0.5923 & $4 I .2 \pm 3.4$ & 0.0077 \\
\hline $5-9$ & $4.4 \pm 0.9$ & & $40.9 \pm 3.6$ & \\
\hline $10-14$ & $4.4 \pm 0.7$ & & $42.1 \pm 2.6$ & \\
\hline$>15$ & $4.5 \pm 0.8$ & & $42.3 \pm 2.8$ & \\
\hline \multicolumn{5}{|l|}{ Monthly } \\
\hline \multicolumn{5}{|l|}{ Income(JD) } \\
\hline$<500$ & $4.3 \pm 0.9$ & 0.1161 & $40.6 \pm 3.2$ & 0.0195 \\
\hline $500-1000$ & $4.3 \pm 0.9$ & & $41.8 \pm 3.1$ & \\
\hline$>1000$ & $4.5 \pm 0.8$ & & $41.4 \pm 3.5$ & \\
\hline
\end{tabular}

Abbreviations: SD, standard deviation; JD, Jordanian Dinar.

measures during daily practice such as wear a face covering while in the hospital setting and hand hygiene are recommended. ${ }^{18,31}$ Salvatori et al reported that a lack of personal protective equipment was cited as the most common cause of COVID-19 associated mortality among physicians. $^{32}$

In a study of 44,672 patients with COVID-19 in China, $81 \%$ of patients had mild manifestations, $14 \%$ had severe manifestations, and 5\% had critical manifestations. ${ }^{33}$ In 
our study, the majority of participants believed that COVID-19 is a very serious issue. However, $21.4 \%$ of participants will refrain from dealing with COVID-19suspected patients. This might explain that participants are afraid of getting infected and dying from the disease, fear of transmitting the infection to their families, and the stigma associated with the disease. According to the Egyptian Medical Syndicate, they reported that 430 physicians were infected with 68 deaths, with COVID-19 mortality rate of $15.8 \%$ until the middle of June $2020 .^{34}$

We found that the basic knowledge mean scores were higher among consultant physicians and physicians working in the university and military hospitals. Furthermore, the mean attitudes scores were different across professional degree, age, and years of experience. This finding was expected as the consultant doctors have more experience, and the university and military staff have more exposure to updated medical information. It was also acceptable to find a high attitude mean score among physicians with high monthly income and years of experience. Our results are significant since they may denote that more effort should be exerted on continuous education during this pandemic, encourage physicians with a higher professional degree, and more experience to be involved during this pandemic. The current finding agrees with Abou-Abbas et al. They conducted a study to assess the level of knowledge and practice among physicians in Lebanon during COVID-19, and they found that the majority of Lebanese physicians had good knowledge. At the same time, approximately half of the respondents adopted good preventive practices. The authors also found that only age was significantly associated with good knowledge, and good practice was two times higher among frontline than the second line workers. Finally, the authors reported that physicians with an experience of 10 years and above were 3.35 times more likely to have good practice than their counterparts. ${ }^{35}$

In contrast, Saqlain et al reported in their study among HCWs in Pakistan that pharmacists had greater knowledge than doctors, but the difference was not significant. ${ }^{36}$ In contrast, Bhagavaathula et al found that doctors had greater knowledge than pharmacists. ${ }^{20}$ This could be due to disparities of knowledge among HCWs. Both doctors and pharmacists are actively involved in seeking information due to their active roles in improving patients' treatment outcomes with COVID-19. ${ }^{36}$

In general, participants in our study had adequate KPA toward COVID-19. These findings could be explained because almost all participants reported that WHO websites and scientific journals are trustworthy scientific information sources. Furthermore, medical information from reliable sources and free access to scientific medical journals were fundamental reasons that helped our participants enhance their KPA toward COVID-19. ${ }^{37,38}$

To the best of our knowledge, this is the first study in Jordan and Palestine that assesses physician's KPA toward the COVID-19 pandemic. The study's strength is that participants were physicians from two countries, various health-care sectors, and different professional degrees, which increases the generalizability of these findings. However, some limitations should be considered. The sample size was small, and the data presented in this study are self-reported and subject to recall bias. Moreover, this is an online cross-sectional survey that could be shared with physicians outside of Jordan and Palestine or shared with non-physicians, which may subject to sample bias.

\section{Conclusion}

The COVID-19 pandemic has caused much morbidity and mortality to patients as well as to physicians worldwide. This is the first study to assess KPA among physicians in Jordan and Palestine toward COVID-19. Our results revealed that physicians in both countries had adequate KPA toward COVID-19. However, there was a significant difference in knowledge level and attitudes between the physicians from different age groups, years of experience, health-care sector, professional degrees, and monthly income. As the global threat of COVID-19 continues to emerge, policymakers should maintain these results by providing continuous education and training for all physicians. Likewise, physicians must continue to follow-up with all the updates about this pandemic.

\section{Disclosure}

The authors declare that there is no conflict of interest regarding the publication of this paper.

\section{References}

1. Li Q, Guan X, Wu P, et al. Early transmission dynamics in Wuhan, China, of novel coronavirus-infected pneumonia. $N$ Engl J Med. 2020;382(13):1199-1207. doi:10.1056/NEJMoa2001316

2. World Health Organization. Novel coronavirus-China; 2020. Available from: http://www.who.Int/csr/don/12-january-2020-novelcoronavirus-china/en. Accessed January 8, 2021.

3. WHO. Director-general's opening remarks at the media briefing on COVID-19-11 march; 2020. Available from: https://www.who.int/dg/ speeches/detail/who-director-general-s-opening-remarks-at-the-mediabriefing-on-covid-19-11-march-2020. 
4. Zhou P, Lou YX, Wang XG, et al. A pneumonia outbreak associated with a new coronavirus of probable bat origin. Nature. 2020;579 (7798):270-273. doi:10.1038/s41586-020-2012-7

5. Wang Y, Wang Y, Chen Y, Qin Q. Unique epidemiological and clinical features of the emerging 2019 novel coronavirus pneumonia (COVID-19) implicate special control measures. J Med Virol. 2020;92(6):568-576. doi:10.1002/jmv.25748

6. Chan JF, Yuan S, Kok KH, et al. A familial cluster of pneumonia associated with the 2019 novel coronavirus indicating person-toperson transmission: a study of a family cluster. Lancet. 2020;2020.

7. Wu ZMJ, McGoogan JM. Characteristics of and important lessons from the coronavirus disease 2019 (COVID-19) outbreak in China: summary of a report of 72314 cases from the Chinese center for disease control and prevention. JAMA. 2020;323(13):1239-1242. doi:10.1001/jama.2020.2648

8. Iyengar KP, Ish P, Upadhyaya GK, Malhotra N, Vaishya RJV, Jain VK. COVID-19 and mortality in doctors. Diabetes Metab Syndr. 2020;14(6):1743-1746. doi:10.1016/j.dsx.2020.09.003

9. Centers for Disease Control and Prevention (CDC). Available from: https://covid.cdc.gov/covid-data-tracker/index.html\#health-carepersonnel.

10. Yoshida I, Tanimoto T, Schiever N, Patelli FKM. Characteristics of doctors' fatality due to COVID-19 in Western Europe and AsiaPacific countries. QJM Int J Med. 2020.

11. Mumbai Mirror. At Least 99 Doctors Succumbed, 1302 Infected in India. 2020.

12. Ing EB, Xu QA, Salimi A, Torun N. Physician deaths from corona virus (COVID-19) disease. Occup Med (Chic Ill). 2020;70 (5):370-374. doi:10.1093/occmed/kqaa088

13. World Health Organization. Available from: https://covid19.who.int. Accessed January 8, 2021.

14. Jordan Ministry of Health; 2020. Available from: https:/corona.moh. gov.jo/en. Accessed January 8, 2021.

15. Palestinian Ministry of Health. Available from: http://site.moh.ps/index/ covid19/LanguageVersion/1/Language/ar. Accessed January 8, 2021.

16. Guan W, Ni Z, Hu Y, et al. Clinical characteristics of coronavirus disease 2019 in China. N Engl J Med. 2020;382(18):1708-1720. doi:10.1056/NEJMoa2002032

17. Khader Y, Al Nsour M, Al-Batayneh OB, et al. Dentists' awareness, perception, and attitude regarding covid-19 and infection control: cross-sectional study among Jordanian dentists. JMIR Public Health Surveill. 2020;6(2):e18798. doi:10.2196/18798

18. Sahu KK, Mishra AK, Lal A. Covid-2019: update on epidemiology, disease spread and management. Monaldi Arch Chest Dis. 2020;90 (1):197-205. doi:10.4081/monaldi.2020.1292

19. Maleki S, Najafi F, Farhadi K, Fakhri M, Hosseini F, Naderi M. Knowledge, Attitude and Behavior of Health Care Workers in the Prevention of COVID-19. 2020:1-17.

20. Bhagavathula AS, Aldhaleei WA, Rahmani J, Mahabadi MA, Bandari DK. Knowledge and perceptions of COVID-19 among health care workers: cross-sectional study. JMIR Public Health Surveill. 2020;6(2):e19160. doi:10.2196/19160

21. Huynh TLD. The COVID-19 containment in Vietnam: what are we doing? J Glob Health. 2020;10(1):10-12. doi:10.7189/jogh.10.010338

22. Chan JF, Yuan S, Kok KH, et al. A familial cluster of pneumonia associated with the 2019 novel coronavirus indicating person-toperson transmission: a study of a family cluster. Lancet. 2020;395 (10223):514-523. doi:10.1016/S0140-6736(20)30154-9

23. Wang D, Hu B, Hu C, et al. Clinical characteristics of 138 hospitalized patients with 2019 novel coronavirus-infected pneumonia in Wuhan, China. JAMA. 2020;323(11):1061-1069. doi:10.1001/jama.2020.1585
24. Richardson S, Hirsch JS, Narasimhan M, et al. Presenting characteristics, comorbidities, and outcomes among 5700 patients hospitalized with COVID-19 in the New York City area. JAMA. 2020;323 (20):2052-2059. doi:10.1001/jama.2020.6775

25. Wu Z, McGoogan JM. Characteristics of and important lessons from the coronavirus disease 2019(COVID-19) outbreak in China. JAMA. 2020;2019. doi:10.1001/jama.2020.2648

26. Onder G, Rezza G, Brusaferro S. Case-fatality rate and characteristics of patients dying in relation to COVID-19 in Italy. JAMA. 2020;323 (18):1775-1776.

27. Zimmermann P, Curtis N. Coronavirus infections in children including COVID-19: an overview of the epidemiology, clinical features, diagnosis, treatment and prevention options in children. Pediatr Infect Dis J. 2020;39(5):355-368. doi:10.1097/INF.0000000000002 660

28. Ludvigsson JF. Systematic review of COVID-19 in children shows milder cases and a better prognosis than adults. Acta Paediatr Int J Paediatr. 2020;109(6):1088-1095. doi:10.1111/apa.15270

29. World Health Organization. Infection prevention and control during health care when COVID-19 is suspected. Available from: https:// www.who.int/publications-detail/infection-prevention-and-controlduring-health-care-when-novelcoronavirus-(ncov)-infection-i.

30. Chow EJ, Schwartz NG, Tobolowsky FA, et al. Symptom screening at illness onset of health care personnel with SARS-CoV-2 infection in King County, Washington. JAMA. 2020;323(20):2087-2089. doi:10.1001/jama.2020.6637

31. Chen Z, Zhang W, Lu Y, et al. From SARS-CoV to Wuhan 2019-nCoV outbreak: similarity of early epidemic and prediction of future trends. bioRxiv. 2020.

32. Euronews. Italian doctor dies of coronavirus after working without gloves due to shortage; 2020. Available from: https://www.euronews. com/2020/03/18/italian-doctor-dies-of-coronavirus-after-workingwithout-gloves-due-to-shortage. Accessed January 8, 2021.

33. CDC Weekly C. The epidemiological characteristics of an outbreak of 2019 novel coronavirus diseases (COVID-19)-China, 2020. China CDC Weekly. 2020;2(8):113-122. doi:10.46234/ccdcw20 20.032

34. Abdel Wahed WY, Hefzy EM, Ahmed MI, Hamed NS. Assessment of knowledge, attitudes, and perception of health care workers regarding COVID-19, a cross-sectional study from Egypt. J Community Health. 2020;45(6):1242-1251. doi:10.1007/s10900020-00882-0

35. Abou-Abbas L, Nasser Z, Fares Y, Chahrour M, El Haidari R, Atoui R. Knowledge and practice of physicians during COVID-19 pandemic: a cross-sectional study in Lebanon. BMC Public Health. 2020;20(1):1-9. doi:10.1186/s12889-020-09585-6

36. Saqlain M, Munir MM, Rehman SU. Knowledge, attitude, practice and perceived barriers among health-care workers regarding COVID-19: a cross-sectional survey from Pakistan. J Hosp Infect. 2020;105(3):419-423. doi:10.1016/j.jhin.2020.05.007

37. Huynh TLD. Data for understanding the risk perception of COVID-19 from Vietnamese sample. Data Br. 2020;30:105530. doi:10.1016/j.dib.2020.105530

38. Huynh TLD. Does culture matter social distancing under the COVID-19 pandemic? Saf Sci. 2020;130:130. doi:10.1016/j. ssci.2020.104872 


\section{Publish your work in this journal}

The International Journal of General Medicine is an international, peer-reviewed open-access journal that focuses on general and internal medicine, pathogenesis, epidemiology, diagnosis, monitoring and treatment protocols. The journal is characterized by the rapid reporting of reviews, original research and clinical studies across all disease areas. The manuscript management system is completely online and includes a very quick and fair peer-review system, which is all easy to use. Visit http://www.dovepress.com/ testimonials.php to read real quotes from published authors.

Submit your manuscript here: https://www.dovepress.com/international-journal-of-general-medicine-journal 